\title{
Positional plagiocephaly: an analysis of the literature on the effectiveness of current guidelines
}

\author{
Faris Shweikeh, B.S., ${ }^{1}$ Miriam Nuño, Ph.D., ${ }^{1}$ Moise Danielpour, M.D., ${ }^{1}$ \\ Mark D. Krieger, M.D., ${ }^{2}$ ANd Doniel Drazin, M.D. ${ }^{1}$ \\ ${ }^{1}$ Department of Neurosurgery, Cedars-Sinai Medical Center; and ${ }^{2}$ Department of Neurosurgery, Children's \\ Hospital of Los Angeles, University of Southern California, Los Angeles, California
}

\begin{abstract}
Object. Positional plagiocephaly (PP) has been on the rise in recent years. In this review, the authors' aim was to assess the effectiveness of current recommendations to parents on this exceedingly common problem through a comprehensive literature search. Additionally, the current treatment options and the most recent studies on PP are reviewed.

Methods. A search of the existing literature was conducted to obtain all relevant studies on guidelines, recommendations, parental and clinician practices, and epidemiological aspects.

Results. Although the incidence and risk factors for PP have been well delineated, there continues to be debates on its management and association with developmental delays. Current guidelines and recommendations on prevention set by the American Association of Pediatrics may not be easily followed by both parents and clinicians. There is also evidence that certain populations, including those with lower education, socioeconomic status, and in particular geographic regions may be more affected by the condition. Additionally, the marketing and financial aspects of PP treatments exist and should be addressed.

Conclusions. Better awareness and education are necessary to inform the population as a whole, although certain populations should be given special attention. Additionally, current guidelines and recommendations can be modified to foster a better grasp of the condition by both parents and clinicians. Adjusting current recommendations, introducing initiatives, and offering elaborate educational campaigns would help deliver these aims. Educating parents on $\mathrm{PP}$ as early as possible through clearer guidelines and close monitoring is central to preventing and managing this common condition.
\end{abstract}

(http://thejns.org/doi/abs/10.3171/2013.8.FOCUS13261)

$\begin{array}{llcl}\text { KEY WoRdS } & \bullet & \text { positional plagiocephaly } \bullet \text { deformational plagiocephaly } \\ \text { guidelines } & \bullet & \text { recommendations } \bullet \text { management } \bullet \text { prevention }\end{array}$

A SYMMETRICAL deformity in an infant's cranium is referred to as plagiocephaly, a condition that has been on the rise over the past few decades following the recommendation to place infants in a supine sleeping position. ${ }^{15,66}$ This term can be used to describe asymmetry in the skull resulting from both nonsynostotic and synostotic causes, or primary premature suture closure, which is much rarer. ${ }^{39}$ Positional plagiocephaly (PP), also referred to as deformational plagiocephaly, occurs in the absence of suture synostosis and is due to external forces that deform the shape of the skull; forces such as those present when infants are placed supine. ${ }^{15}$ In this condition there is flattening of one side of the occiput, with anterior

Abbreviations used in this paper: $\mathrm{AAP}=$ American Academy of Pediatrics; BTS = "Back to Sleep"; PP = positional plagiocephaly; $\mathrm{PT}=$ physical therapy; $\mathrm{RCT}=$ randomized controlled trial; SIDS = sudden infant death syndrome; TT = "Tummy Time." displacement of the ipsilateral ear. The region of occipital flattening relates to the side that the head is toward when in the supine sleeping position. ${ }^{5}$ Prior to the American Academy of Pediatrics (AAP) "Back to Sleep" (BTS) campaign, the incidence of PP was relatively low. ${ }^{45}$ Following this recommendation there was a gradual rise in its incidence, making it currently an especially common presentation at physicians' offices.

Considering the alarming increase in the incidence of PP, there has been much interest in investigating, managing, and preventing this condition. Figure 1 outlines the increase in publications concerning the deformity over recent decades.

Our aim, through a comprehensive literature search, was to assess the impact and effectiveness of the current guidelines and recommendations to parents. In addition, we reviewed current treatment options and we provide an update on the most recent studies regarding managing and preventing PP. 


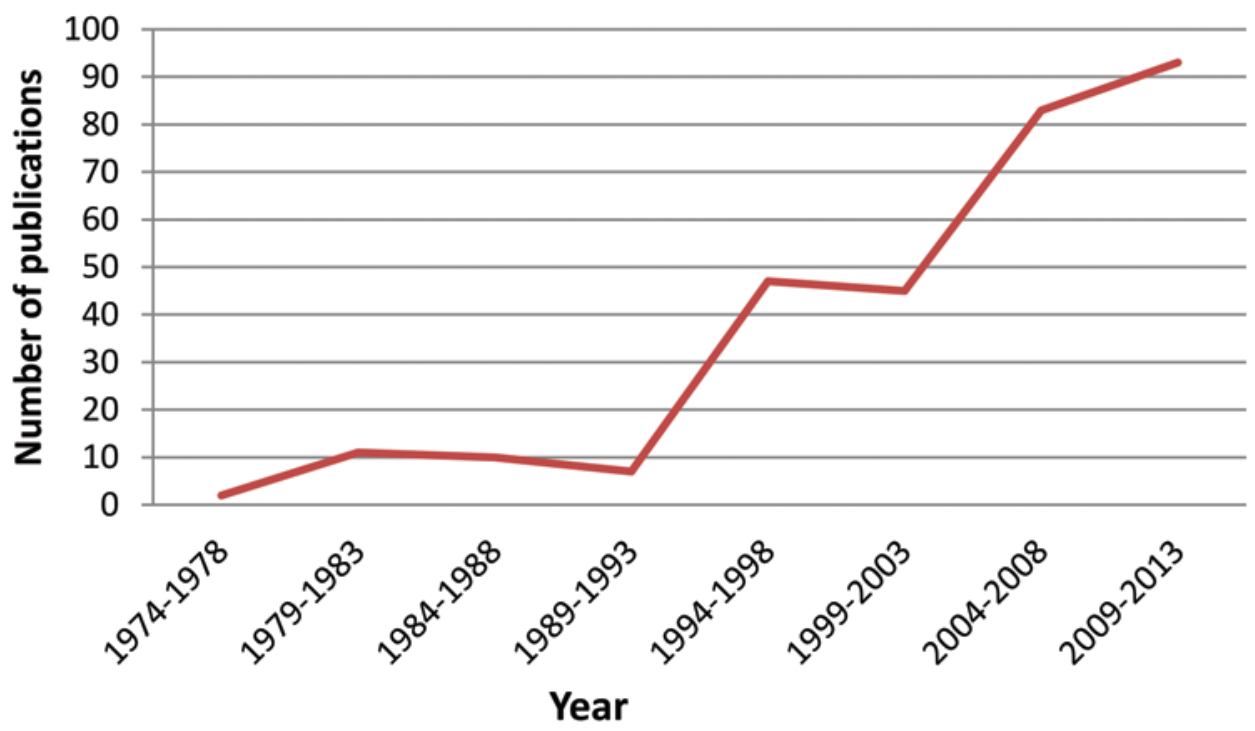

FIG. 1. Graph showing number of publications concerning plagiocephaly between 1974 and the present. Note the increase beginning in 1996, a few years after the "Back to Sleep" campaign began.

\section{Methods}

A search on the National Library of Medicine search engine, PubMed, was conducted using the following terms: "positional plagiocephaly," "deformational plagiocephaly," "plagiocephaly guidelines," "plagiocephaly recommendations," and "plagiocephaly epidemiology." Relevant articles on PP that covered aspects of current guidelines and/or recommendations, parental or clinician practices, risk factors, socioeconomic factors, or that were epidemiological were selected. Additionally, the reference lists from these selected articles were examined for other relevant papers. Overall, 15 articles were found to be relevant and were examined closely to match the aims of this review.

At the same time, previously published systematic reviews on the topic were used in reviewing current treatment options. Clinical studies in which there was a high level of evidence, as alluded to by evaluating these systematic reviews, were selected and reviewed. Additionally, we sought to provide an update on the most recent studies since the last systematic review. Studies that were published afterward were obtained based on a search with these terms: "positional plagiocephaly" and "deformational plagiocephaly." Clinical reports in which there was new and/or relevant information on the current status of the condition were chosen and are reviewed here.

\section{Results}

\section{General Considerations and Factors}

Positional plagiocephaly is a common diagnosis. The incidence of PP varies with infant age, with an incidence of $19.7 \%$ at its peak and 3.3\% at its lowest. ${ }^{15,27}$ Misdiagnosis is common and the condition may be confused with lambdoid synostosis. Therefore, a detailed examination of the infant's cranium is necessary. The risk factors for PP are numerous; they include both prebirth and postbirth causalities. ${ }^{15,65,68}$ Most significant are supine sleeping and congenital torticollis. Mostly recently, controversy over whether the deformity is associated with lower developmental abilities has sparked multiple debates..$^{39,54}$

\section{Guidelines and Recommendations}

In 1992, the AAP announced their recommendation of placing infants on their backs while asleep to combat the risk of sudden infant death syndrome (SIDS), ${ }^{1,36}$ Within a few years of this "Back to Sleep" campaign, as it became known, what had been a relatively uncommon diagnosis rapidly began to increase in incidence. There was a dramatic increase in publications concerning PP shortly after this recommendation (Fig. 1). Studies began to emerge on the effect of this new sleeping position on infant milestones. $17,19,36,41,58$ The AAP's "Tummy Time" (TT) recommendation to parents was intended to decrease the likelihood of both skull deformation and lag in developmental skills. This called for placing infants on their stomachs while awake and overseen by the parent. The guideline was bolstered by multiple studies, $, 48,54,68$ although the potential difficulty in orchestrating it among both parents and clinicians was highlighted by others. ${ }^{10,17,36,68}$

\section{Socioeconomic and Environmental Considerations}

The perception of a "normal" head shape can depend on many factors, including family opinion, cultural background, ethnicity, genetic makeup, and different time periods. ${ }^{3,6,23,39,51}$ Some reports have pointed to poor knowledge and awareness of the condition in parents with lower education levels. ${ }^{9,60,68}$ There is also a question of whether some parents may be refusing recommendations because of misconceptions. ${ }^{10,17,68}$ Another study investigated the rise in PP incidence in the state of Texas for a significant number of years following the 1992 recommendation and found that it was mainly attributed to an increase in the number of referrals, although the reason for that increase could only be speculated upon.$^{60}$ Last, the publicity about 
the condition and marketing of its treatments, particularly cranial orthoses, cannot be denied..$^{54}$

\section{Update of the Recent Literature}

Four systematic reviews on the condition have been published, $, 20,39,54,70$ with the last one covering the literature up until the early part of 2011..$^{20,39}$ These evidencebased studies report on the current situation of management through a number of quality studies (Table 1), although there is a scarcity of randomized controlled trials (RCTs). The literature continues to reflect the high interest in this topic among various pediatric and craniofacial circles. Since then, many new clinical studies have been added to the literature, including 1 prospective clinical trial. ${ }^{8}$ Table 2 lists 2 previous studies detailing surgical aspects specifically of PP. We reviewed a number of these newer studies in our update (Table 3).

\section{Discussion}

\section{Extent of the Problem}

The current incidence of PP is estimated at $8.2 \%$, with variations according to infant age. ${ }^{7,34}$ Its frequency is significant at the age of 6 weeks, with estimates of $16 \%$; it peaks at 4 months with $19.7 \%$, and then declines gradually at the age of 2 years to $3.3 \% .^{15,27}$ These estimates are closely related to the infant's development. The first weeks of life are accompanied by poor head positioning, worsening $\mathrm{PP},{ }^{41}$ followed by a period of normal development during which the head shape slightly improves. During the subsequent stage the infant is not able to prop the rapidly growing head on his/her own until age 4 months, which corresponds to the peak $(19.7 \%)$ at this time. The frequency of PP then begins to level down, with a normalization in shape by 6 months as the infant gains active control of the head. ${ }^{39,44}$ Unfortunately, there has been an accompanying false increase in the rate of synostotic plagiocephaly due to misdiagnosis and a lack of ability to differentiate the 2 conditions, leading to unnecessary referrals. ${ }^{26}$

Craniosynostosis is an important differential diagnosis, particularity the lambdoid type. Though relatively infrequent, it characteristically presents with bossing in the occipitomastoid region and posterior shifting of the ear. ${ }^{15}$ A palpable bony elevation along the lambdoid suture is also usually present. ${ }^{33}$ Additionally, bilateral coronal synostosis has the potential to present with brachycephaly. ${ }^{6} \mathrm{~A}$ thorough physical examination can distinguish between the 2 entities in almost all cases. In rare instances when the diagnosis remains indeterminate, skull imaging studies may be helpful to rule out this more serious condition and to initiate surgical intervention. More importantly, referral to a neurosurgeon and/or a craniofacial clinic is warranted.

\section{Established Risk Factors}

Aspects that increase the likelihood of PP have been well delineated and include supine sleeping, bottle feeding, male sex, congenital torticollis, being awake fewer than 3 times a day (so-called tummy time), and lower activity level. ${ }^{15,27,68}$ Other studies have proposed obstetric concerns such as constraints of the birth canal on firstborn babies, prolonged labor, breech position, assisted deliveries, intrauterine restrictions, and plural births. ${ }^{39,54,63}$ The impact of supine sleeping position on PP is best illustrated by the AAP's 1992 recommendation for infants to sleep on their backs. ${ }^{1}$ This BTS campaign decreased the incidence of SIDS by more than $40 \%$, but increased consultations for PP by $600 \% .^{2,39,48}$ In terms of neck problems, torticollis is the most common associated abnormality and most likely occurs prior to the formation of PP. ${ }^{39,57}$ It has been estimated to occur in up to one-sixth of infants and to be highly underdiagnosed..$^{39,65}$ The issue of torticollis needs to be recognized early and managed as a distinct entity because it has major repercussions on PP development and treatment.

The evidence circulating about the lower activity level and developmental delays and its association with PP is controversial. ${ }^{39,54}$ Previously, nonsynostotic plagiocephaly was acknowledged to be unrelated to abnormal neurological development. ${ }^{39,46}$ More recently, however, studies have built a possible association between disruptions in infant development and PP. ${ }^{10,21,28,30,63}$ Multiple reports over the past decade have pointed to links between PP and abnormal ophthalmological findings, auditory processing, and motor development. 4,10,25,27,28,35,44,47,62,63,68 Two case-controlled studies, by Speltz et al. ${ }^{63}$ and Fowler et al., ${ }^{21}$ found significant variability in gross motor development and body tone. However, almost none of these studies account for sleep position and many have problems with their design, suggesting that there are probably other factors at play. ${ }^{53,54}$ With that being so, at this point the best recommendation for clinicians is to closely monitor their patients' neurological development. ${ }^{39,54}$

\section{Evaluating the AAP Guidelines}

Both of the AAP's recommendations (BTS and TT) have profoundly impacted the plagiocephaly abnormality. ${ }^{1,36}$ With the BTS recommendation to prevent SIDS, a corresponding increase in PP frequency began to emerge, which in turn brought about the TT suggestion to parents. ${ }^{36}$ Interestingly, at the same time, newer studies pointed out that since implementation of BTS recommendations and the resulting increase in supine sleeping, infant motor milestones began to be attained later. ${ }^{17,36,41}$ In a prospective study of 351 infants, it was found that prone sleepers achieved a number of motor milestones at an earlier age than supine sleepers, and another similar study reported similar lags in motor skills. ${ }^{41}$ However, in both studies supine sleepers eventually caught up in their motor development at latest follow-up. Multiple other analyses have also highlighted the influence of sleep position on infant motor performance. ${ }^{19,58}$ DudekShriber and Zelazny ${ }^{19}$ determined that the time spent in the prone position while awake (or in TT) was directly correlated to earlier achievement of milestones, whether they were prone milestones, supine milestones, or sitting milestones. Importantly, as in previous reports, ${ }^{17,58}$ the authors called attention to infants who did not tolerate the prone position while awake and how it directed parents to discontinue the position. 
F. Shweikeh et al.
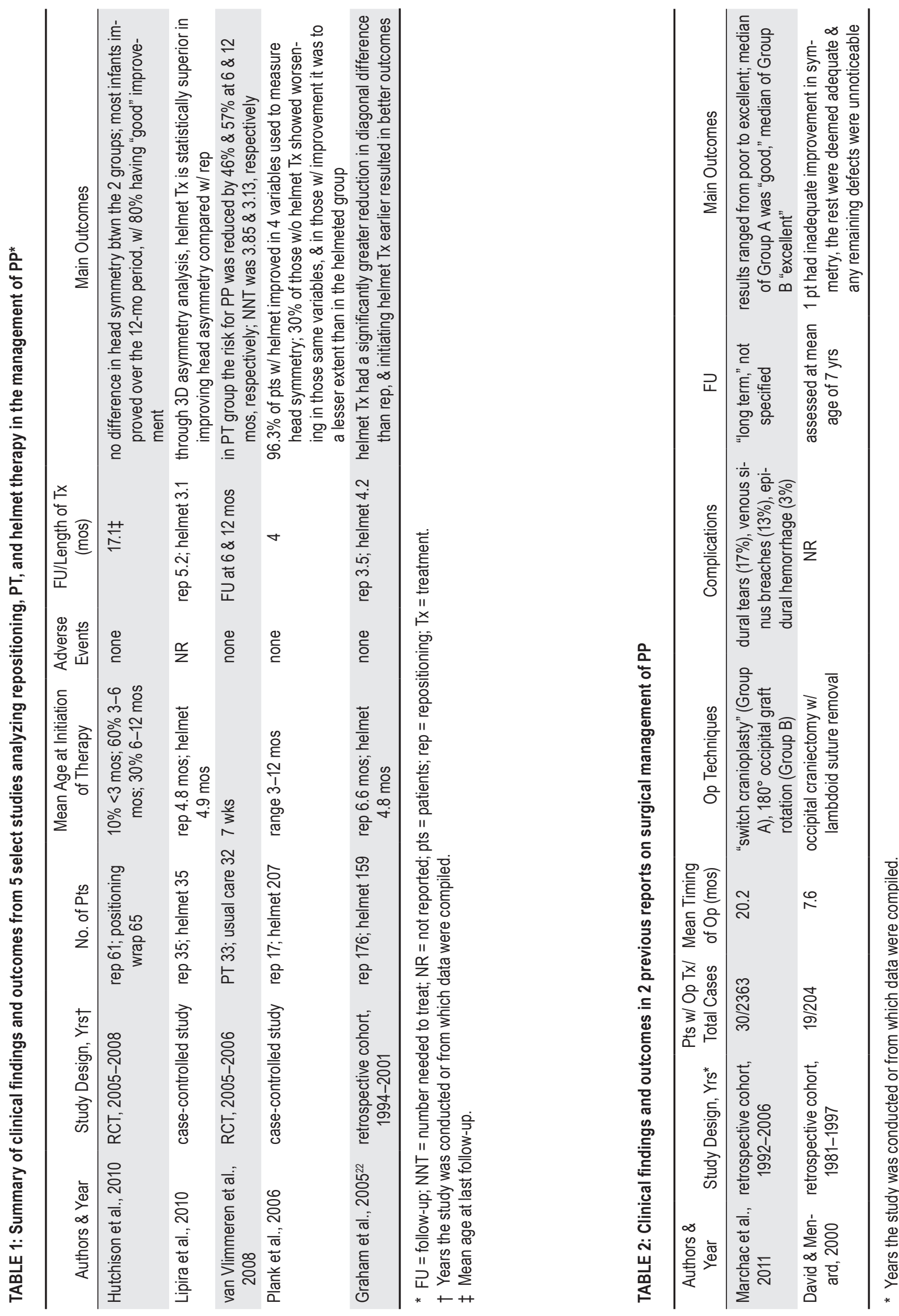
Positional plagiocephaly guidelines analysis

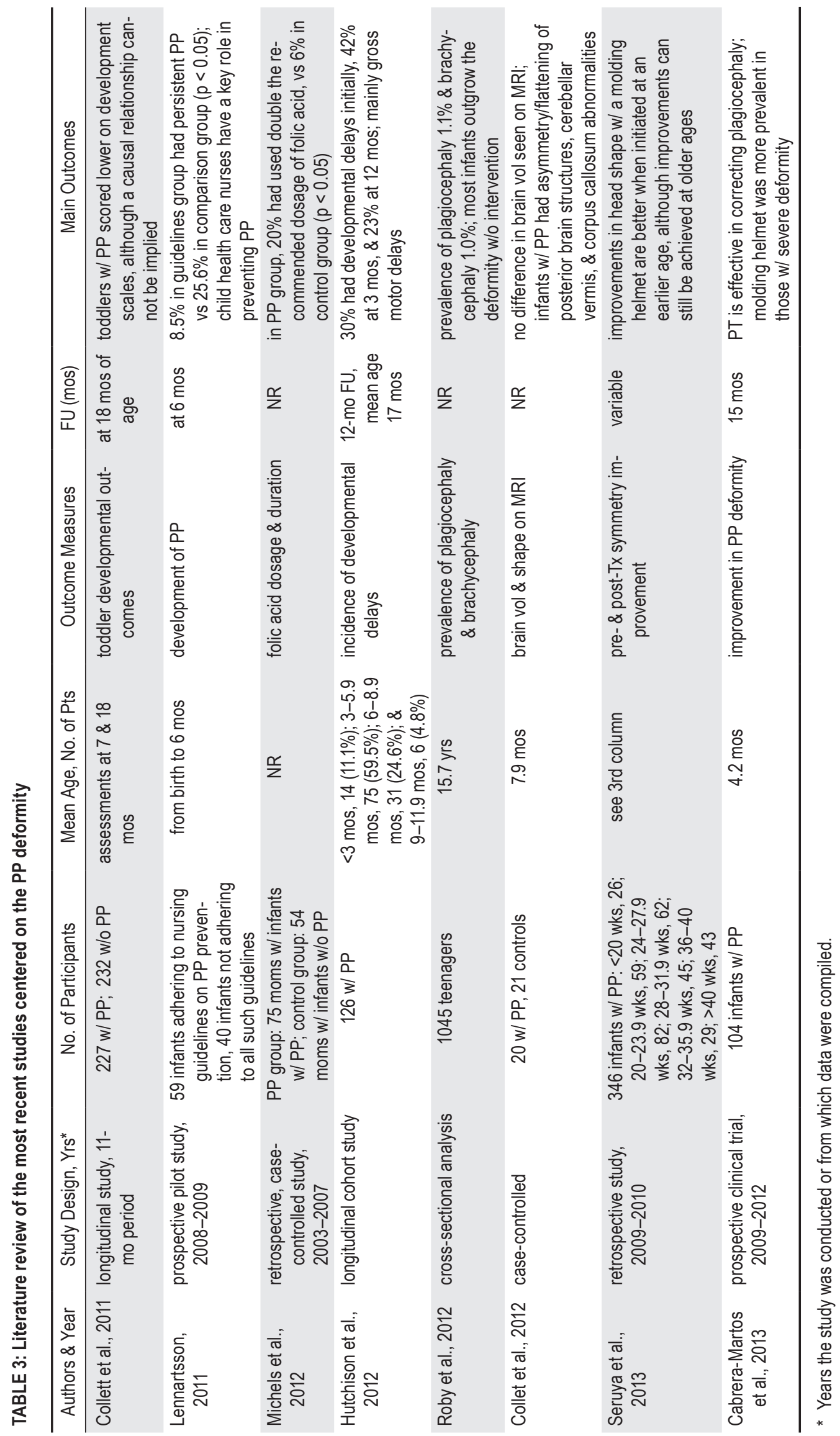




\section{F. Shweikeh et al.}

The second AAP guideline to parents (TT) called for a certain length of time for the infant to be awake in the prone position to prevent head distortion and improve motor development. At least 30 minutes of TT while awake can significantly diminish the predisposition for PP formation. ${ }^{48,54}$ Van Vlimmeren et al. ${ }^{68}$ conducted a large-cohort study to analyze risk factors for PP in infants at 7 weeks of age. They found that fewer than 3 TT sessions per day, along with a poor attainment of motor milestones, had a significant association with PP. In a prospective and controlled study, Cavalier et al. ${ }^{9}$ investigated environmental factors on PP prevalence in 139 newborns. The intervention group in the study was instructed to alternate infant sleeping positions, to have prone position time while the infant was awake, to minimize time in car seats, and to promote an environment that allowed spontaneous movement. It was found that these practices decreased PP prevalence in the intervention group (13\%) when compared with the control group $(31 \%)(\mathrm{p}<0.001)$ at 4 months of age. It is difficult to ascertain from this or previous studies whether there is a direct causation of PP by poor motor development, or vice versa. It is important to highlight, however, that the report by van Vlimmeren et al. revealed significant findings related to a mother's educational level and its impact on PP. Mothers with low educational levels were more likely to offer TT for the first time at more than 3 weeks of age, more likely to position their infants on the same side during bottle feeding, and more likely to offer bottle feeding only. It is thus plausible that parents with low educational levels provide briefer and more infrequent TT to their children, decreasing position change and hindering motor growth, which in turn results in the PP abnormality. ${ }^{68}$

In the most recent AAP recommendations for parents, the revised TT section advises that the practice should begin as early as possible and should increase in frequency and length with time. ${ }^{36}$ Even though the recent guidelines provided suggestions on how to avoid head asymmetry and how to promote TT in infants, the recommendations still had ambiguities just like their predecessors. ${ }^{36}$ Because there is evidence that some parents may be misconstruing the AAP's TT recommendation and others are completely unwilling to place their infants prone, ${ }^{10,17,68}$ parents should be clearly educated about PP, its causes, and possible effects. Koren et al. ${ }^{36}$ attempted to investigate these glitches in communication and comprehension among both parents and clinicians, and their results were eye-opening. They found multiple obstacles for implementing TT including frustrated and unhappy infants, time limitations for the parents, and uncertainty regarding recommendations. Barriers cited by clinicians for educating parents about TT were emphasis on SIDS, time constraints, and also confusion. Additionally, Internet resources on the topic provided variable and unclear information. Their study determined that a surprisingly low percentage of mothers received information on awake TT both at the child's birth (55\%) and at 2 months (26\%), that most of the mothers (71\%) practiced TT twice per day or less, and that more than half of the infants were in TT for 3-5 minutes or less. In fact, propping the infant in a supine position when awake was the most frequent finding. More resources should be used to prevent development of this condition, especially in more affected populations.

\section{Assessing the Effect of Socioeconomics and Geography}

Cultural backgrounds and practices can influence what is deemed to be a normal head shape. In ancient periods and cultures, certain practices to deliberately deform an infant's skull were a norm and part of social status. ${ }^{3,39}$ Brachycephaly, the condition in which there is entire flattening of the occiput, is customarily found in many Asian countries where infants traditionally sleep in the supine position. ${ }^{23,39}$ The cephalic index, or the ratio of the width of the head to its length, has been reported to be as high as $91 \%$ in Japan's and Korea's schoolchildren. Conversely, in Nigeria, an infant's cephalic index can be as low as $75 \%$ because traditionally they are placed in the prone position for sleep. ${ }^{39}$ Infant cephalic index in the US has seen a corresponding change from a mean of $78 \%$ in the 1970s to a range of $86 \%-88 \%$ in the 2000 s as a result of changes in sleep position recommendations. ${ }^{23,39}$ Furthermore, it is imperative to compare an infant's head shape to that of his/her parents and to factor in the role of heredity along with environment during assessment. ${ }^{51}$

Sheu et al. ${ }^{60}$ explored aspects involved in the 9-fold increase in plagiocephaly in Texas between 1999 and 2007. The prevalence of PP had increased an average of $21.2 \%$ per year, resulting in an incidence of 28.8 cases per 10,000 live births (up from 3 cases per 10,000 live births in 1999). These investigators found that the increasing trend was similar regardless of demographic factors such as maternal age, race/ethnicity, infant sex, and gestational age. However, the trend was greatest in mothers with less education $(\mathrm{p}=0.01)$, as had been reported previously. The authors pointed out that the common assertion that the AAP's BTS campaign was responsible for the drastic increase during that period cannot be supported because their study was conducted more than 7 years after the introduction of BTS, although a minimal part of the increase could be due to delayed compliance. They attributed another small increase in incidence to an increase in preterm births. However, factors such as changes in birth defect coding, incidence of multiple births, torticollis, and oligohydramnios were ruled out. Interestingly, they noticed that major increases were seen mostly at certain self-prescribed "craniofacial clinics" or other similar specialized facilities. It is highly likely that these facilities fostered an increase in consultations and thus in diagnosis and treatment of PP. However, the increase in referrals could not be explained and could only be speculated on, with issues such as decision of the primary care physician, parental wishes, reimbursement incentives, and increased publicity about PP and its treatment options as probable reasons. Sheu et al. concluded that modifications in therapeutic options and insurance compensation policies could be likely to be contributing to the increased prevalence.

The preceding study brings into question 2 other important issues: 1) the marketing and financial aspects of PP treatments; and 2) the impact of income and race. First, the issue of increased publicity about PP and marketing of its therapies has its roots in 1998, when cranial orthoses became categorized as Class II devices by the FDA as a 
result of petitioning by a commercial corporation, Cranial Technologies. ${ }^{54}$ This forced independent orthotic specialists who had worked directly with pediatric neurosurgeons to provide inexpensive orthoses to those in need, to either contract with large companies, or to acquire their own FDA approval. ${ }^{54}$ This, along with the sweeping marketing of therapies and the media coverage that ensued, created a massive rise in the cost of the orthoses and tremendous concern surrounding the condition on the part of parents. Unfortunately, the rise in cost caused many insured patients and those with Medicaid to lose coverage of these helmets for their children. Second, the issues of income and race have been well documented to be factors in limiting families from appropriately following the infant supine sleeping recommendations for prevention of SIDS. ${ }^{13,14}$ Barriers within low-income and African American populations have been cited as a cause and include absence of information or advice, receiving wrong advice, loss of trust in health care workers, apprehension about infant safety and comfort, and lack of knowledge about risks involved.14 It can only be assumed that these barriers are also applicable to recommendations on PP prevention such as TT. Furthermore, the study by Sheu et al. provides evidence for a need to concentrate efforts on another more endemically affected population, that in the Southern region of the US.

\section{Current Treatment Options}

Over the last decade there have been 2 RCTs and 4 systematic reviews that analyzed management of PP., 5 , 28,39,54,67,70 For nonsynostotic plagiocephaly, treatment options include alternate head positioning, physical therapy (PT), and helmet therapy. ${ }^{15} \mathrm{~A}$ recent $\mathrm{RCT}$ determined that adding PT is superior to parental counseling on head positioning alone. ${ }^{15,67}$ Therapy with a molding helmet has also shown a significant improvement in skull shape, with 1 study indicating relative improvement in skull shape in comparison with repositioning therapy. ${ }^{15,22}$ Generally, mild disfigurement should be managed with repositioning techniques and PT, whereas helmet orthosis is reserved for more serious defects, especially lasting past the age of 6 months. ${ }^{54}$

Because the conventional treatment of PP is multifaceted, the literature is vast but remains limited. In their retrospective cohort, Graham et al. ${ }^{22}$ reported on 176 infants treated with repositioning and 159 treated with a molding helmet. They found that the reduction in diagonal difference was better with orthotics than with repositioning $(0.71$ vs 0.55 , $\mathrm{p}<0.0001)$. Although treatment with a helmet required a longer time, the earlier it was initiated the more effective the outcomes were. In 2006, Plank et al. ${ }^{49}$ reported on 207 helmeted infants, compared them with a control group of 17 infants, and determined that there was much greater deformity improvement with helmet therapy. More recently, Lipira et al. ${ }^{38}$ reported on a study that used 3D imaging analysis on 35 helmeted infants compared with 35 repositioned infants, and found that the former group had a higher percent decline in head asymmetry (4\% vs $2.5 \%$; $\mathrm{p}=0.02$ ). In an RCT conducted in New Zealand, a total of 126 infants received either repositioning therapy alone or repositioning combined with a positioning wrap. ${ }^{28}$ No difference was found in outcomes after 12 months of follow- up, with $80 \%$ of infants displaying "good" improvement. In another RCT assessing the utility of PT, van Vlimmeren et al. ${ }^{67}$ assigned 33 patients to PT and 32 to usual care. The PT group was determined to have a lower risk of PP at both 6 and 12 months (46\% and 57\%, respectively). These studies are summarized in Table 1.

The surgical management of PP is rare, and has even been criticized, because it is deemed to be unwarranted for PP treatment. ${ }^{56}$ Because there is no evidence that it can cause elevations in intracranial pressure, and the association with delays in development is questionable at best, it leaves aesthetic considerations as the only reason to consider a risky surgery. ${ }^{56}$ Others have pointed out that head asymmetry eventually improves with time and seldom worsens beyond 4 months, ${ }^{16,45,50,52,56,69}$ suggesting that watchful waiting rather than invasive surgery is a more reasonable option. However, the more recent evidence indicates that the deformity may not improve after 15 months of age, ${ }^{24,32,40,48,61,64}$ which brings to the table another highly controversial issue surrounding PP. Another argument proposed for surgical adjustment involved those who are referred at a later age when remodeling of the skull is no longer possible. ${ }^{18}$

\section{An Update: Most Recent Studies}

Since the last systematic review, ${ }^{20,39}$ multiple studies have been published on the subject (Table 3), reflecting the great interest in the topic in the pediatric, neurosurgical, and craniofacial worlds. Collett et al. ${ }^{12}$ found that toddlers with a history of PP have developmental (motor, cognitive, and language) delays relative to those without such a history, although the investigators concluded that it does not imply a causal relationship. Furthermore, the reported developmental scores were still within the normal range, and long-term follow-up would be more beneficial. ${ }^{31}$ Along the same lines, Hutchison et al. ${ }^{29}$ found that although patients with PP do have gross motor delays initially, when these patients are followed for a longer period the presence of these delays drops to expected levels. Roby et al. ${ }^{55}$ explored the presence of PP and brachycephaly in teenagers born after the BTS campaign and found an overall prevalence of $2 \%$ for deformational abnormalities, suggesting that in most infants the deformity eventually resolves. A Swedish pilot study demonstrated a significant reduction in incidence when guidelines for PP prevention were followed by nurses (8.5\% vs $25.6 \%$ incidence in the comparison group, $\mathrm{p}<0.05)$, and concluded that applying simple strategies in child health care programs can help parents prevent PP. ${ }^{37}$ A Dutch study investigated another potential factor to consider for PP that was also fueled by its own campaign over the past 2 decades: folic acid..$^{43}$ The study found that women whose infants had PP were more likely to have taken double the recommended dosage of folic acid during their pregnancy than those whose infants did not have PP (20\% vs $6 \%$, respectively; $\mathrm{p}<0.05)$.

\section{Conclusions}

Positional plagiocephaly is a common condition in infants that has been rife with controversy in many of its 
aspects including its natural history, the grading schemes assessing its severity, the value of its multiple treatments, the financial incentives and commercial parties involved, and doctor/parent understanding and implementation of preventive measures. These controversies are not expected to be resolved in the near future. Better awareness and education are necessary to the population as a whole, although certain populations such as lower socioeconomic and Southern populations should be given special attention. Additionally, current guidelines and recommendations can be modified to foster a better grasp of the condition by both parents and clinicians. Along with new initiatives and elaborate campaigns, educating parents on PP as early as possible is central to avoiding and managing this exceedingly frequent problem.

\section{Disclosure}

The authors report no conflict of interest concerning the materials or methods used in this study or the findings specified in this paper.

Author contributions to the study and manuscript preparation include the following. Conception and design: Drazin, Shweikeh, Danielpour, Krieger. Acquisition of data: Shweikeh, Nuño. Analysis and interpretation of data: Drazin, Shweikeh. Drafting the article: Drazin, Shweikeh, Nuño. Critically revising the article: Drazin, Shweikeh, Danielpour, Krieger. Reviewed submitted version of manuscript: all authors. Approved the final version of the manuscript on behalf of all authors: Drazin. Administrative/technical/material support: Nuño. Study supervision: Drazin, Shweikeh, Danielpour, Krieger.

\section{References}

1. American Academy of Pediatrics Task Force on Infant Positioning and SIDS: Positioning and SIDS. Pediatrics 89:1120_ 1126, 1992 (Erratum in Pediatrics 90:264, 1992)

2. Argenta LC, David LR, Wilson JA, Bell WO: An increase in infant cranial deformity with supine sleeping position. J Craniofac Surg 7:5-11, 1996

3. Ayer A, Campbell A, Appelboom G, Hwang BY, McDowell M, Piazza M, et al: The sociopolitical history and physiological underpinnings of skull deformation. Neurosurg Focus 29(6):E1, 2010

4. Balan P, Kushnerenko E, Sahlin P, Huotilainen M, Näätänen R, Hukki J: Auditory ERPs reveal brain dysfunction in infants with plagiocephaly. J Craniofac Surg 13:520-526, 2002

5. Bialocerkowski AE, Vladusic SL, Wei Ng C: Prevalence, risk factors, and natural history of positional plagiocephaly: a systematic review. Dev Med Child Neurol 50:577-586, 2008

6. Blaser SI: Abnormal skull shape. Pediatr Radiol 38 (Suppl 3):S488-S496, 2008

7. Boere-Boonekamp MM, van der Linden-Kuiper LT: Positional preference: prevalence in infants and follow-up after two years. Pediatrics 107:339-343, 2001

8. Cabrera-Martos I, Valenza MC, Benítez-Feliponi A, RoblesVizcaíno C, Ruiz-Extremera A, Valenza-Demet G: Clinical profile and evolution of infants with deformational plagiocephaly included in a conservative treatment program. Childs Nerv Syst [epub ahead of print], 2013

9. Cavalier A, Picot MC, Artiaga C, Mazurier E, Amilhau MO, Froye E, et al: Prevention of deformational plagiocephaly in neonates. Early Hum Dev 87:537-543, 2011

10. Collett B, Breiger D, King D, Cunningham M, Speltz M: Neurodevelopmental implications of "deformational" plagiocephaly. J Dev Behav Pediatr 26:379-389, 2005

11. Collett BR, Aylward EH, Berg J, Davidoff C, Norden J, Cun- ningham ML, et al: Brain volume and shape in infants with deformational plagiocephaly. Childs Nerv Syst 28:1083-1090, 2012

12. Collett BR, Starr JR, Kartin D, Heike CL, Berg J, Cunningham ML, et al: Development in toddlers with and without deformational plagiocephaly. Arch Pediatr Adolesc Med 165: $653-658,2011$

13. Colson ER, Levenson S, Rybin D, Calianos C, Margolis A, Colton T, et al: Barriers to following the supine sleep recommendation among mothers at four centers for the Women, Infants, and Children Program. Pediatrics 118:e243-e250, 2006

14. Colson ER, McCabe LK, Fox K, Levenson S, Colton T, Lister $\mathrm{G}$, et al: Barriers to following the back-to-sleep recommendations: insights from focus groups with inner-city caregivers. Ambul Pediatr 5:349-354, 2005

15. Cummings C: Positional plagiocephaly. Paediatr Child Health (Oxford) 16:493-496, 2011

16. David DJ, Menard RM: Occipital plagiocephaly. Br J Plast Surg 53:367-377, 2000

17. Davis BE, Moon RY, Sachs HC, Ottolini MC: Effects of sleep position on infant motor development. Pediatrics 102:11351140, 1998

18. Di Rocco F, Marchac A, Duracher C, Perié AC, Vergnaud E, Renier D, et al: Posterior remodeling flap for posterior plagiocephaly. Childs Nerv Syst 28:1395-1397, 2012

19. Dudek-Shriber L, Zelazny S: The effects of prone positioning on the quality and acquisition of developmental milestones in four-month-old infants. Pediatr Phys Ther 19:48-55, 2007

20. Flannery AB, Looman WS, Kemper K: Evidence-based care of the child with deformational plagiocephaly, part II: management. J Pediatr Health Care 26:320-331, 2012

21. Fowler EA, Becker DB, Pilgram TK, Noetzel M, Epstein J, Kane AA: Neurologic findings in infants with deformational plagiocephaly. J Child Neurol 23:742-747, 2008

22. Graham JM Jr, Gomez M, Halberg A, Earl DL, Kreutzman JT, Cui J, et al: Management of deformational plagiocephaly: repositioning versus orthotic therapy. J Pediatr 146:258-262, 2005

23. Graham JM Jr, Kreutzman J, Earl D, Halberg A, Samayoa C, Guo X: Deformational brachycephaly in supine-sleeping infants. J Pediatr 146:253-257, 2005

24. Gruss JS, Ellenbogen RG, Whelan MF: Lambdoid synostosis and posterior plagiocephaly, in Lin KY, Ogle RC, Jane JA (eds): Craniofacial Surgery: Science and Surgical Technique. Philadelphia: WB Saunders, 2002, pp 233-251

25. Gupta PC, Foster J, Crowe S, Papay FA, Luciano M, Traboulsi EI: Ophthalmologic findings in patients with nonsyndromic plagiocephaly. J Craniofac Surg 14:529-532, 2003

26. Huang MH, Gruss JS, Clarren SK, Mouradian WE, Cunningham ML, Roberts TS, et al: The differential diagnosis of posterior plagiocephaly: true lambdoid synostosis versus positional molding. Plast Reconstr Surg 98:765-776, 1996

27. Hutchison BL, Hutchison LA, Thompson JM, Mitchell EA: Plagiocephaly and brachycephaly in the first two years of life: a prospective cohort study. Pediatrics 114:970-980, 2004

28. Hutchison BL, Stewart AW, De Chalain TB, Mitchell EA: A randomized controlled trial of positioning treatments in infants with positional head shape deformities. Acta Paediatr 99:1556-1560, 2010

29. Hutchison BL, Stewart AW, de Chalain T, Mitchell EA: Serial developmental assessments in infants with deformational plagiocephaly. J Paediatr Child Health 48:274-278, 2012

30. Hutchison BL, Stewart AW, Mitchell EA: Characteristics, head shape measurements and developmental delay in 287 consecutive infants attending a plagiocephaly clinic. Acta Paediatr 98:1494-1499, 2009

31. Hutchison L: Deformational plagiocephaly is associated with developmental delay in toddlers. J Pediatr 160:527-528, 2012 
32. Joganic JL, Lynch JM, Littlefield TR, Verrelli BC: Risk factors associated with deformational plagiocephaly. Pediatrics 124:e1126-e1133, 2009

33. Kabbani H, Raghuveer TS: Craniosynostosis. Am Fam Physician 69:2863-2870, 2004

34. Kalra R, Walker ML: Posterior plagiocephaly. Childs Nerv Syst 28:1389-1393, 2012

35. Kordestani RK, Patel S, Bard DE, Gurwitch R, Panchal J: Neurodevelopmental delays in children with deformational plagiocephaly. Plast Reconstr Surg 117:207-220, 2006

36. Koren A, Reece SM, Kahn-D'angelo L, Medeiros D: Parental information and behaviors and provider practices related to tummy time and back to sleep. J Pediatr Health Care 24:222230,2010

37. Lennartsson F: Testing guidelines for child health care nurses to prevent nonsynostotic plagiocephaly: a Swedish pilot study. J Pediatr Nurs 26:541-551, 2011

38. Lipira AB, Gordon S, Darvann TA, Hermann NV, Van Pelt AE, Naidoo SD, et al: Helmet versus active repositioning for plagiocephaly: a three-dimensional analysis. Pediatrics 126: e936-e945, 2010

39. Looman WS, Flannery AB: Evidence-based care of the child with deformational plagiocephaly, Part I: assessment and diagnosis. J Pediatr Health Care 26:242-250, 2012

40. Loveday BP, de Chalain TB: Active counterpositioning or orthotic device to treat positional plagiocephaly? J Craniofac Surg 12:308-313, 2001

41. Majnemer A, Barr RG: Association between sleep position and early motor development. J Pediatr 149:623-629, 2006

42. Marchac A, Arnaud E, Di Rocco F, Michienzi J, Renier D: Severe deformational plagiocephaly: long-term results of surgical treatment. J Craniofac Surg 22:24-29, 2011

43. Michels AC, Van den Elzen ME, Vles JS, Van der Hulst RR: Positional plagiocephaly and excessive folic acid intake during pregnancy. Cleft Palate Craniofac J 49:1-4, 2012

44. Miller RI, Clarren SK: Long-term developmental outcomes in patients with deformational plagiocephaly. Pediatrics 105:E26, 2000

45. O'Broin ES, Allcutt D, Earley MJ: Posterior plagiocephaly: proactive conservative management. Br J Plast Surg 52:18-23, 1999

46. Panchal J, Amirsheybani H, Gurwitch R, Cook V, Francel P, Neas B, et al: Neurodevelopment in children with single-suture craniosynostosis and plagiocephaly without synostosis. Plast Reconstr Surg 108:1492-1500, 2001

47. Peitsch WK, Keefer CH, LaBrie RA, Mulliken JB: Incidence of cranial asymmetry in healthy newborns. Pediatrics 110:e72, 2002

48. Persing J, James H, Swanson J, Kattwinkel J, Committee on Practice and Ambulatory Medicine, Section on Plastic Surgery, Section on Neurological Surgery: Prevention and management of positional skull deformities in infants. Pediatrics 112:199-202, 2003

49. Plank LH, Giavedoni B, Lombardo JR, Geil MD, Reisner A: Comparison of infant head shape changes in deformational plagiocephaly following treatment with a cranial remolding orthosis using a noninvasive laser shape digitizer. J Craniofac Surg 17:1084-1091, 2006

50. Pollack IF, Losken HW, Fasick P: Diagnosis and management of posterior plagiocephaly. Pediatrics 99:180-185, 1997

51. Pomatto JK, Calcaterra J, Kelly KM, Beals SP, Manwaring KH, Littlefield TR: A study of family head shape: environment alters cranial shape. Clin Pediatr (Phila) 45:55-63, 2006

52. Pople IK, Sanford RA, Muhlbauer MS: Clinical presentation and management of 100 infants with occipital plagiocephaly. Pediatr Neurosurg 25:1-6, 1996

53. Robinson S: Deformational plagiocephaly delays motor skill development in 6-month-old infants. J Pediatr 157:514-515, 2010
54. Robinson S, Proctor M: Diagnosis and management of deformational plagiocephaly. A review. J Neurosurg Pediatr 3:284-295, 2009

55. Roby BB, Finkelstein M, Tibesar RJ, Sidman JD: Prevalence of positional plagiocephaly in teens born after the "Back to Sleep" campaign. Otolaryngol Head Neck Surg 146:823828,2012

56. Rogers GF: Severe deformational plagiocephaly: long-term results of surgical treatment. J Craniofac Surg 22:30-32, 2011

57. Rogers GF, Oh AK, Mulliken JB: The role of congenital muscular torticollis in the development of deformational plagiocephaly. Plast Reconstr Surg 123:643-652, 2009

58. Salls JS, Silverman LN, Gatty CM: The relationship of infant sleep and play positioning to motor milestone achievement. Am J Occup Ther 56:577-580, 2002

59. Seruya M, Oh AK, Taylor JH, Sauerhammer TM, Rogers GF: Helmet treatment of deformational plagiocephaly: the relationship between age at initiation and rate of correction. Plast Reconstr Surg 131:55e-61e, 2013

60. Sheu SU, Ethen MK, Scheuerle AE, Langlois PH: Investigation into an increase in plagiocephaly in Texas from 1999 to 2007. Arch Pediatr Adolesc Med 165:708-713, 2011

61. Shin JH, Persing J: Asymmetric skull shapes: diagnostic and therapeutic consideration. J Craniofac Surg 14:696-699, 2003

62. Siatkowski RM, Fortney AC, Nazir SA, Cannon SL, Panchal J, Francel P, et al: Visual field defects in deformational posterior plagiocephaly. J AAPOS 9:274-278, 2005

63. Speltz ML, Collett BR, Stott-Miller M, Starr JR, Heike C, Wolfram-Aduan AM, et al: Case-control study of neurodevelopment in deformational plagiocephaly. Pediatrics 125: 537 e542, 2010

64. Stallings MW: Management of positional skull deformities: who needs a helmet? Pediatrics 113:422-424, 2004

65. Stellwagen L, Hubbard E, Chambers C, Jones KL: Torticollis, facial asymmetry and plagiocephaly in normal newborns. Arch Dis Child 93:827-831, 2008

66. Turk AE, McCarthy JG, Thorne $\mathrm{CH}$, Wisoff JH: The "back to sleep campaign" and deformational plagiocephaly: is there cause for concern? J Craniofac Surg 7:12-18, 1996

67. van Vlimmeren LA, van der Graaf Y, Boere-Boonekamp MM, L'Hoir MP, Helders PJ, Engelbert RH: Effect of pediatric physical therapy on deformational plagiocephaly in children with positional preference: a randomized controlled trial. Arch Pediatr Adolesc Med 162:712-718, 2008

68. van Vlimmeren LA, van der Graaf Y, Boere-Boonekamp MM, L'Hoir MP, Helders PJ, Engelbert RH: Risk factors for deformational plagiocephaly at birth and at 7 weeks of age: a prospective cohort study. Pediatrics 119:e408-e418, 2007

69. Vles JS, Colla C, Weber JW, Beuls E, Wilmink J, Kingma $\mathrm{H}$ : Helmet versus nonhelmet treatment in nonsynostotic positional posterior plagiocephaly. J Craniofac Surg 11:572-574, 2000

70. Xia JJ, Kennedy KA, Teichgraeber JF, Wu KQ, Baumgartner JB, Gateno J: Nonsurgical treatment of deformational plagiocephaly: a systematic review. Arch Pediatr Adolesc Med 162: 719-727, 2008

Manuscript submitted July 22, 2013.

Accepted August 7, 2013.

Please include this information when citing this paper: DOI: 10.3171/2013.8.FOCUS13261.

Address correspondence to: Doniel Drazin, M.D., Department of Neurosurgery, Cedars-Sinai Medical Center, Maxine Dunitz Neurosurgical Institute, $8631 \mathrm{~W}$. Third St., Suite 800E, Los Angeles, CA 90048. email: doniel.drazin@cshs.org. 